\title{
TECNOLOGIA DE PROCESSOS E SISTEMAS CONSTRUTIVOS
}

\section{PROCESS TECHNOLOGY AND BUILDING SYSTEMS}

Luciana Alves de Oliveira ${ }^{1}$

Instituto de Pesquisas Tecnológicas, São Paulo - SP

Editora Convidada luciana@ipt.br

Sidney Piochi Bernardini 2

Universidade Estadual de Campinas, Faculdade de Engenharia Civil, Arquitetura e Urbanismo,

Campinas - SP

Editor-chefe

sidpiochi@fec.unicamp.br

Daniel de Carvalho Moreira ${ }^{3}$ Universidade Estadual de Campinas, Faculdade de Engenharia Civil, Arquitetura e Urbanismo,

Campinas - SP Editor-chefe damore@fec.unicamp.br

\section{Editorial}

O terceiro número do Volume 9 de 2018 da PARC Pesquisa em Arquitetura e Construção inclui na seção de Comunicações três artigos, em versão expandida, apresentados no $1^{\circ}$ WORKSHOP DO GRUPO DE TRABALHO DE TECNOLOGIA DE PROCESSOS E SISTEMAS CONSTRUTIVOS (TECSIC), da Associação Nacional de Tecnologia no Ambiente Construído ANTAC, que ocorreu em agosto de 2017, na Universidade Estadual de Campinas. Este Grupo de Trabalho, recém-formado na ANTAC, tem o objetivo de discutir e incentivar pesquisas em três principais temas: tecnologia de materiais, componentes ou sistemas construtivos; processos de produção incluindo fabrica ou canteiro de obras, e controles da qualidade; e requisitos, critérios e métodos de avaliação de desempenho técnico incluindo a segurança estrutural, segurança contra o fogo, estanqueidade à agua e ao ar e durabilidade.

O primeiro artigo, desta seção de comunicações, é dos autores Raimundo Fagner Freitas Kochem e Silvana De Nardin - da Universidade Federal de São Carlos - e apresenta a tecnologia de piso misto de pequena altura, o qual é considerado como sistema misto de aço e concreto por se tratar da associação entre viga mista e laje mista. A principal característica desse piso é o embutimento da viga na laje, o que proporciona redução da altura total do sistema laje-viga aumentando o pé-direito do pavimento. O artigo mostra os principais componentes e as técnicas inerentes ao processo construtivo, incluindo equipamentos necessários à sua execução.

Alex Roda Maciel, Fabiano Rogerio Corrêa e Mércia Bottura de Barros, da Universidade de São Paulo, desenvolvem uma pesquisa visando analisar a interface digital entre o projeto e o processo industrial de aço cortado e dobrado e o uso do processo BIM no Projeto de Detalhamento de Armadura (PDA). Trata-se de uma pesquisa inédita no meio acadêmico, cujos resultados mostram que ainda há muito que desenvolver para melhorar os processos de produção, principalmente, considerando ferramentas digitais.

$\mathrm{O}$ artigo dos autores Wallison Angelim Medeiros e Guilherme Aris Parsekian, também da Universidade Federal de São Carlos, argumenta que as paredes em alvenaria podem ser consideradas como elemento de contraventamento de estruturas pré-moldadas de concreto, desde que certas condições sejam

How to cite this article:

OLIVEIRA, Luciana Alves de; BERNARDINI, Sidney Piochi; MOREIRA, Daniel de Carvalho. Tecnologia de processos e sistemas construtivos. PARC Pesquisa em Arquitetura e Construção, Campinas, SP, v. 9, n. 3, p. 164-166, set. 2018. ISSN 1980-6809. Disponível em:

<https://periodicos.sbu.unicamp.br/ojs/index.php/parc/article/view/8653494>. Acesso em: 27 set. 2018. doi:https://doi.org/10.20396/parc.v9i3.8653494. 
atendidas. $\mathrm{O}$ artigo introduz também a importante discussão da influência dos detalhes construtivos da interface/ligação entre parede e estrutura para a eficiência dessa premissa estrutural.

Tales Lobosco e Débora Carvalho Câmara, da Universidade Federal de Minas Gerais, desenvolvem um modelo qualitativo didático, de baixo custo, que visa promover uma compreensão intuitiva do comportamento mecânico das estruturas. $\mathrm{O}$ modelo permite flexibilidade de montagens para a exploração de diversas possibilidades estruturais, servindo como uma ferramenta de aprendizado e experimentação. É possível a visualização do comportamento mecânico das estruturas, evidenciando as deformações, torções e flechas, de maneira a permitir a correlação intuitiva dos fenômenos observados com as simulações numéricas computacionais. São discutidas aplicações e limitações.

Lucia Teresinha Peixe Maziero, da Pontifícia Universidade Católica do Paraná, abrange estratégias de Aprendizagem Ativa para o ensino de Topografia para estudantes de Arquitetura e Urbanismo utilizando estratégias de Aprendizagem Ativa. A autora analisou o uso de diferentes modelos de ensino formando um panorama de técnicas e tendências que promovem o aprendizado contextualizado à realidade profissional. Realizou-se o redesenho metodológico e observou-se o oferecimento de uma disciplina. Destaca-se o "foco na aprendizagem significativa em dimensões cognitivas superiores de conceitos, procedimentos técnicos, simulação e modelagem do terreno na concepção projetual, sem prejudicar" a fundamentação requerida em topografia.

Finalizamos este número com duas Revisões Sistemáticas da Literatura alinhadas com a temática de tecnologia de processos e sistemas construtivos.

Pedro Henrique Pinto Bezerra, Adriana de Paula Lacerda Santos e Sergio Scheer, da Universidade Federal do Paraná, investigam as contribuições da utilização da Modelagem da Informação da Construção (BIM) no planejamento de obras residenciais com painéis préfabricados. Os autores realizam uma Revisão Sistemática da Literatura (RSL) abrangendo dois repositórios de publicações online: ScienceDirect e ASCE Library, incluindo também buscas no Google Acadêmico e no portal Periódicos Capes. Os termos de busca foram panelized construction, BIM e social housing. A amostra resultante da RSL é caracterizada pelo foco da tecnologia aplicada ao planejamento de obras com painéis préfabricados e o aprimoramento do processo de produção destes elementos, metodologia ou ferramentas BIM utilizadas e resultados obtidos.

A Revisão Sistemática da Literatura desenvolvida por Fernanda Almeida Machado e Regina Coeli Ruschel - da Universidade Estadual de Campinas - identifica, analisa e estratifica, em classes de problemas, os componentes, modelos e métodos de soluções existentes que integram BIM e Internet das Coisas (IoT). Observa-se majoritariamente soluções para a fase de Operação e Manutenção da edificação e interesse crescente na fase de Construção e Comissionamento. São discriminados as séries e os usos do modelo BIM empregados em cada contexto, bem como as tecnologias utilizadas. Apontamse novos campos de pesquisa em um estágio post-BIM para um contexto multidisciplinar. A revisão é um excelente ponto de partida para novos estudos na temática.

Assim, o terceiro número do Volume 9 de 2018 da PARC Pesquisa em Arquitetura e Construção é composto por artigos de pesquisa e de revisões sistemáticas da literatura desenvolvidos por pesquisadores dos estados brasileiros de Minas Gerais, São Paulo e Paraná. As instituições de ensino e pesquisa envolvidas nos estudos apresentados são: Pontifícia Universidade Católica do Paraná, Universidade de São Paulo, Universidade Estadual de Campinas, Universidade Federal de Minas Gerais, Universidade Federal do Paraná e Universidade Federal de São Carlos. As áreas de formação dos autores concentramse em Engenharia Civil, na maioria, incluindo Arquitetura e Urbanismo e Engenharia Mecatrônica. A temática de tecnologia de processo e sistemas construtivos foi abordada com enfoque em componentes de piso e de fechamento estrutural, ambos em concreto, e automação do processo industrial de aço cortado e dobrado. Os artigos de pesquisa tiveram enfoque no ensino do comportamento mecânico das estruturas e da topografia, em ambos os casos, para estudantes de Arquitetura e Urbanismo. As revisões sistemáticas da literatura abordam pesquisas em Modelagem da Informação da Construção integrada ao planejamento de obras com painéis pré-fabricados e a Internet das Coisas. Desejamos a todos uma boa leitura. 


\section{Agradecimentos}

Agradecemos aos avaliadores pelo tempo despendido e valiosas considerações tecidas sobre os artigos submetidos.

\section{${ }^{1}$ Luciana Alves de Oliveira}

Engenheira Civil. Doutora em Engenharia de Construção Civil (EPUSP), Pesquisadora no Instituto de Pesquisas Tecnológicas do Estado de São Paulo - IPT. Endereço postal: Rua Prof. Almeida Prado, 532, Cidade Universitária, São Paulo, SP, Brasil, CEP: 05508-000.

\section{${ }^{2}$ Sidney Piochi Bernardini}

Arquiteto Urbanista. Doutor em Arquitetura e Urbanismo (FAU-USP). Professor Doutor na Faculdade de Engenharia Civil, Arquitetura e Urbanismo da UNICAMP. Endereço postal: Av. Albert Einstein, 951, Campinas, SP, Brasil, CEP 13.083-852.

\footnotetext{
${ }^{3}$ Daniel de Carvalho Moreira

Arquiteto Urbanista. Doutor em Engenharia Civil (UNICAMP). Professor Doutor II na Faculdade de Engenharia Civil, Arquitetura e Urbanismo da UNICAMP. Endereço postal: Av. Albert Einstein, 951, Campinas, SP, Brasil, CEP 13.083-852.
} 